\title{
The Relationship between Emotional Contagion and Mood State
}

Kayleigh Crow

Dominican University of California

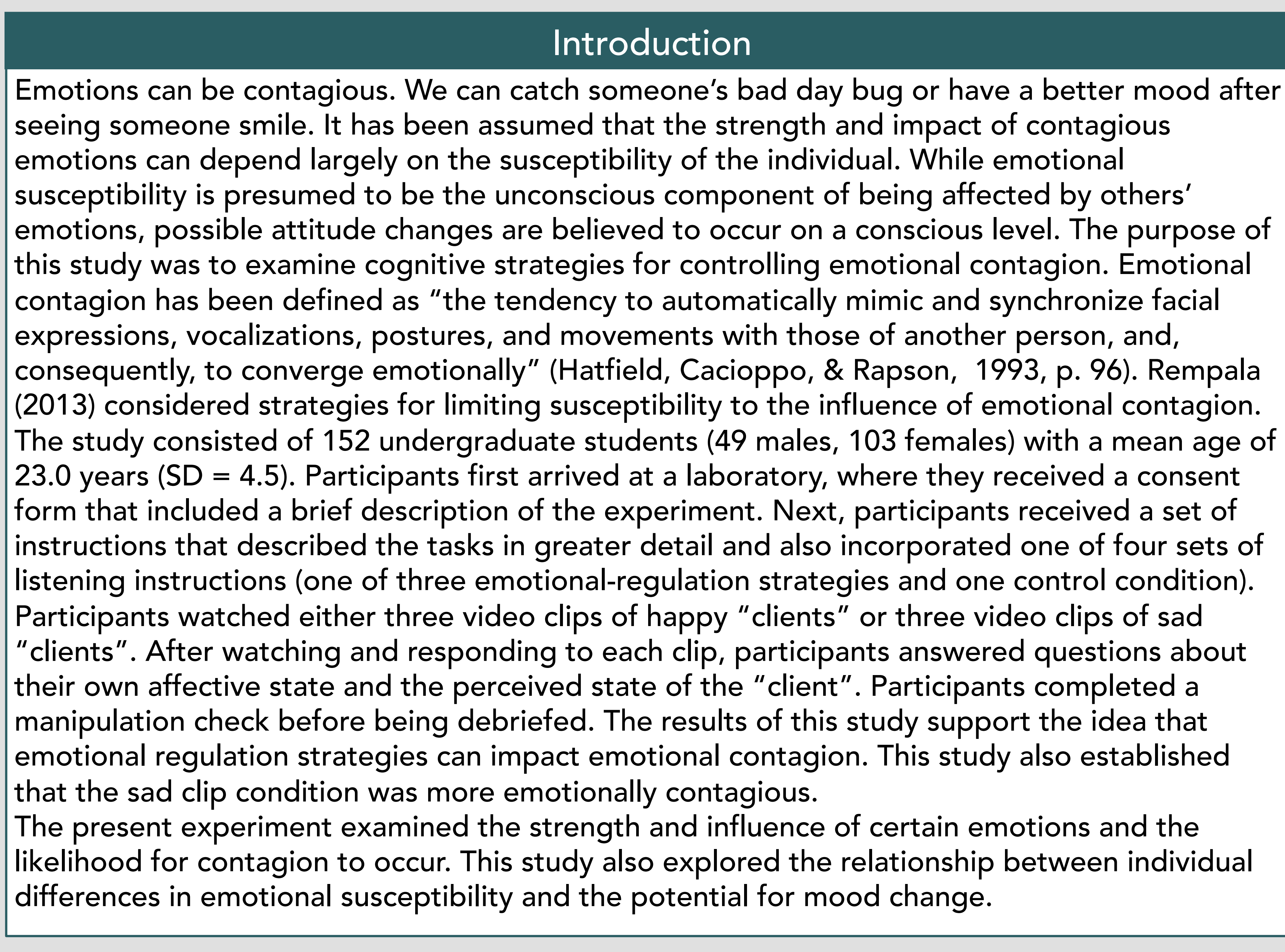

Hypotheses
It was hypothesized that 1) emotionally susceptible people should score high on a mood scale atter watching an emotionally charged video clip, 2) sadness will
and 3) females score higher than males in emotional contagion.

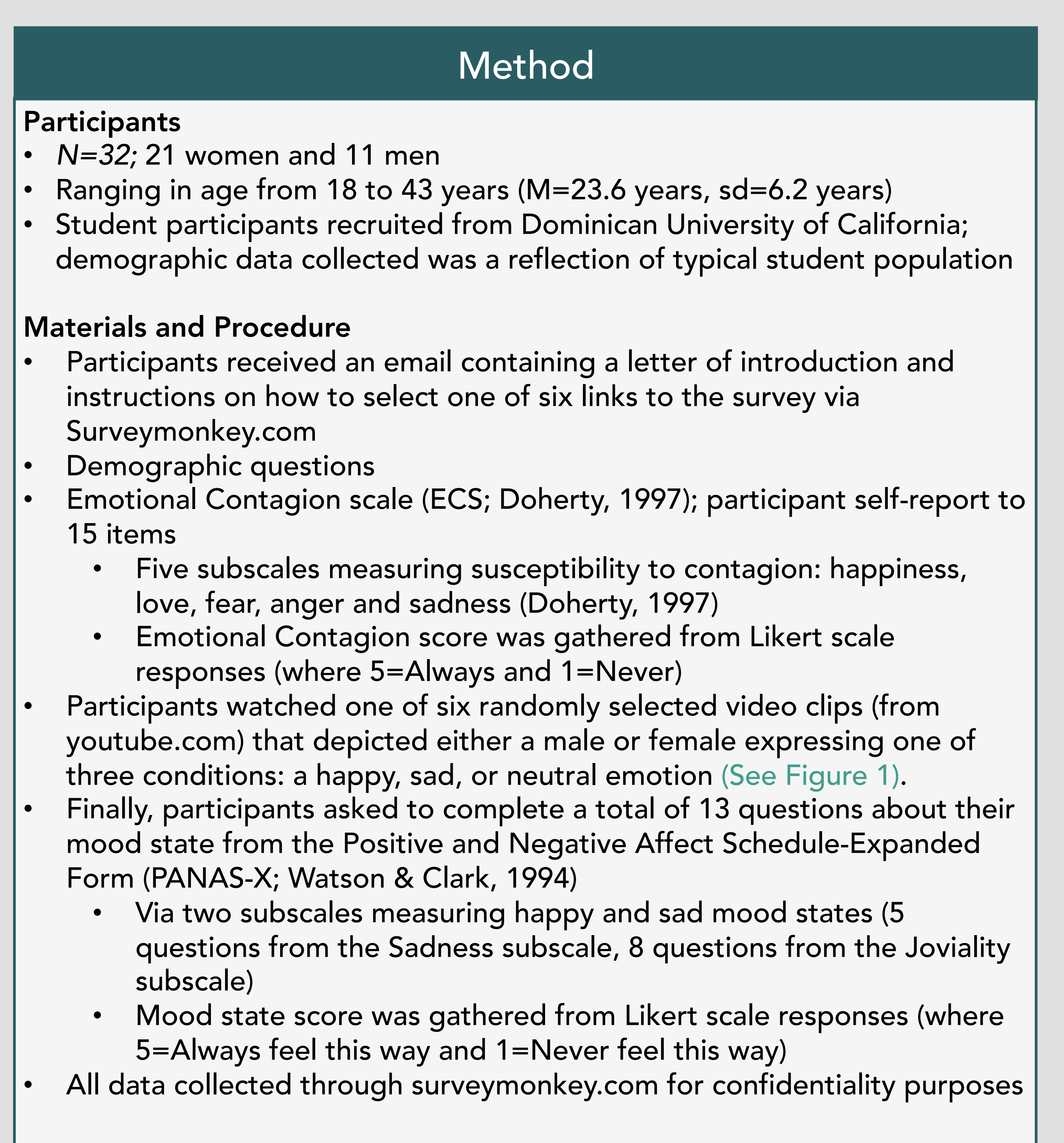
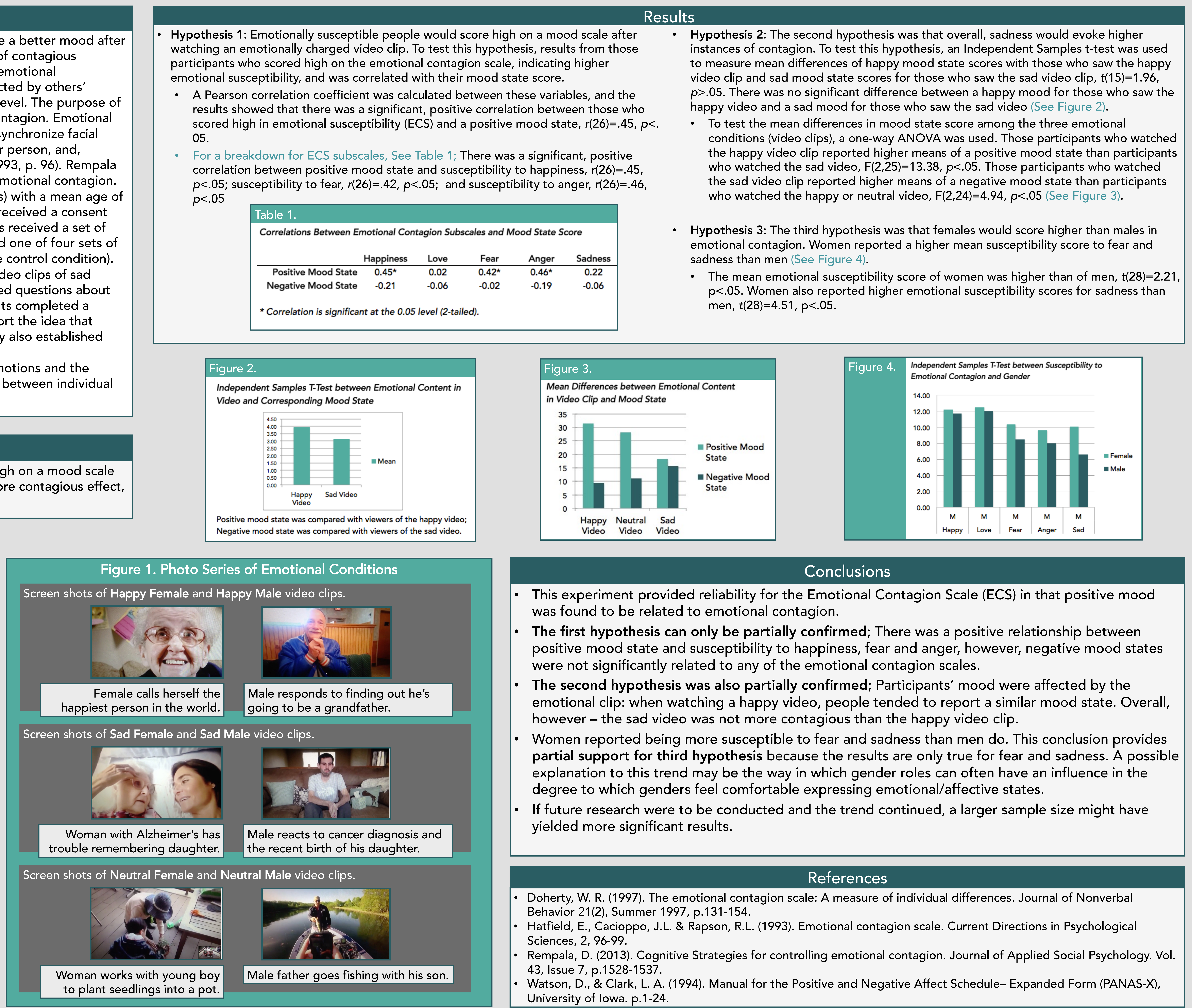
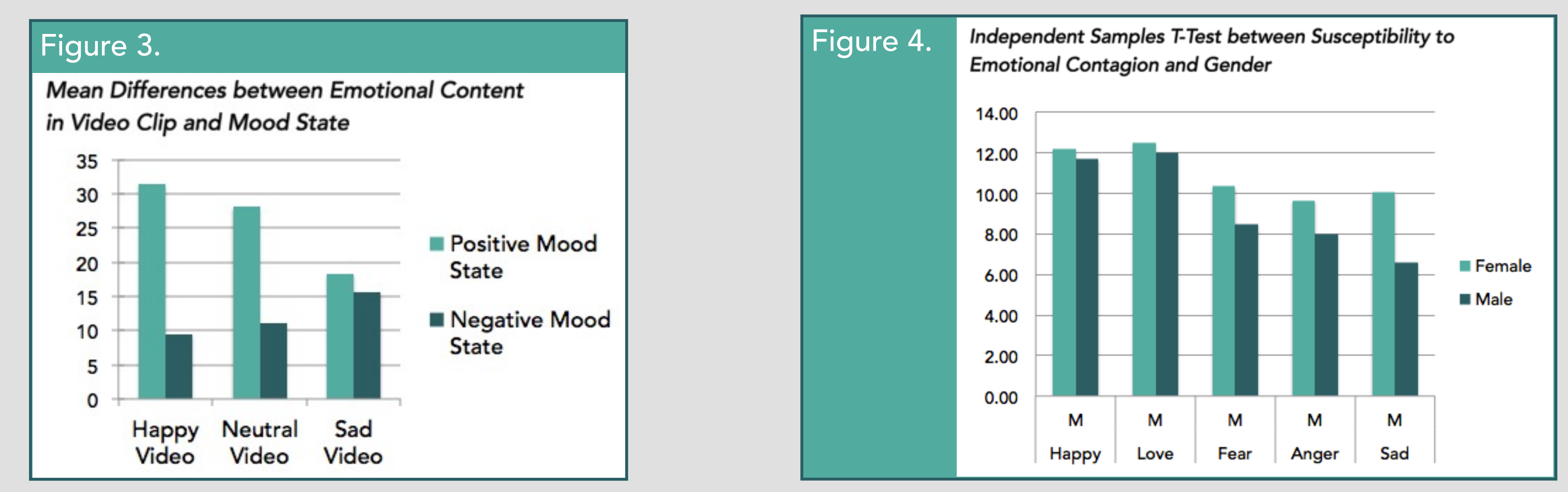

Conclusions

This experiment provided reliability for the Emotional Contagion Scale (ECS) in that positive mood was found to be related to emotional contagion.

The first hypothesis can only be partially confirmed; There was a positive relationship between The first hypothesis can only be partially confirmed; There was a positive relationship between
positive mood state and susceptibility to happiness, fear and anger, however, negative mood states were not significantly related to any of the emotional contagion scales.

The second hypothesis was also partially confirmed; Participants' mood were affected by the The second hypothesis was also partially confirmed; Participants' mood were affected by the
emotional clip: when watching a happy video, people tended to report a similar mood state. Overall emotional clip: when watching a happy video, people tended to report a simila
however - the sad video was not more contagious than the happy video clip.

Women reported being more susceptible to fear and sadness than men do. This conclusion provides Women reported being more susceptible to fear and sadness than men do. This conclusion provides
partial support for third hypothesis because the results are only true for fear and sadness. A possible partial support for third hypothesis because the results are only true for fear and sadness. A pos degree to which genders feel comfortable expressing emotional/affective states.

If future research were to be conducted and the trend continued, a larger sample size might have If future research were to be conduch
yielded more significant results.

References
Doherty, W. R. (1997). The emotional contagion scale: A measure of individual differences. Journal of Nonverbal
Behavior 21 (2), Summer 1997, p.131-154.
Hatfield, E., Cacioppo, J.L. \& Rapson, R.L. (1993). Emotional contagion scale. Current Directions in Psychological
Sciences, 2, 96-99.) Cognitive Strategies for controlling emotional contagion. Journal of Applied Social Psychology. Vol.
Rempala, D. (2013). Co3nitive
43, Issue 7, p.1528-1537.
Watson, D., \& Clark, L. A. (1994). Manual for the Positive and Negative Affect Schedule- Expanded Form (PANAS-X),
University of lowa. P.1-24.

